\title{
Characteristics of tracheostomy phonation
}

\section{valves}

\author{
H. Prigent*, D. Orlikowski*, M.B. Blumen\# ${ }^{\#}$ K. Leroux ${ }^{\star}$, L. Legrand*, M. Lejaille*, \\ L. Falaize*, M. Ruquet*, J-C. Raphael* and F. Lofaso*,+
}

ABSTRACT: Phonation valves are commonly used devices that allow the restoration of speech in tracheostomised patients. However, their use should not compromise the physiological benefit of tracheostomy.

Six commercialised phonation valves were studied in a dynamic set-up simulating a respiratory frequency of 20 breaths $\cdot \mathrm{min}^{-1}$, a tidal volume of $0.5 \mathrm{~L}$ and a peak flow rate of $0.5 \mathrm{~L} \cdot \mathrm{s}^{-1}$. Resistance and additional work of breathing (WOB) were calculated. In 10 tracheostomised patients, evaluations using no phonation valve (baseline), and the most and one of the least resistive valves were carried out. Respiratory patterns and gas exchanges were recorded. Inspiratory difficulty was evaluated using the modified Borg scale.

Valves displayed a wide array of resistance ranging 1.3-5.9 $\mathrm{cmH}_{2} \mathrm{O} \cdot \mathrm{L}^{-1} \cdot \mathrm{s}^{-1}$. Additional WOB varied with a ratio of 4.4 between the best and the worst valve. While the different clinical conditions did not modify respiratory patterns and gas exchanges, a significant effect on the Borg scale rating was observed using ANOVA and post hoc analysis of baseline versus worst valve and one of the best valves versus worst valve.

In conclusion, the variety of aerodynamic characteristics of phonation valves should be considered when choosing the device, according to the underlying condition of the patients benefiting from their use.

KEYWORDS: Phonation valve, resistance, respiratory load, speaking valve, tracheostomy

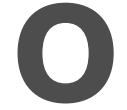
ver the last few decades, mechanical ventilation has become a major treatment for chronic respiratory failure, improving the prognosis of neuromuscular diseases [1, 2]. While it can be conducted noninvasively, tracheostomy can be required either when progression of respiratory disease results in the impossibility of maintaining adequate ventilation through the upper airways or when ventilation weaning is impossible after an acute episode of respiratory failure [3].

One of the main purposes of tracheostomy is to reduce airway resistances and extrathoracic dead space by bypassing upper airways [4, 5]. Tracheostomy can reduce work of breathing (WOB) by $>30 \%[6,7]$. However, loss of verbal communication is one of the main disadvantages of this technique [8, 9]. Patients who are ventilated continuously can obtain restoration of speech if ventilation can be conducted using a cuffless tracheotomy tube [10]. Adjustments of ventilatory mode can allow an improvement in speech during ventilation [11, 12]. Patients who retain respiratory autonomy can use respiratory valves during periods of free breathing. These devices allow the patients to inspire through the tracheostomy tube, while the closure of the valve during expiration directs flow towards the upper airways, thus permitting speech [13].

However, the adjunct of these devices should not compromise the benefit obtained with tracheostomy.

The current authors sought to study the properties of various commonly used phonation valves and to evaluate the additional resistances and WOB imposed on patients through the use of these devices. Additionally, the most and one of the least resistive phonation valves were tested in 10 subjects to determine if the differences between the valves were clinically relevant.

\section{MATERIALS AND METHODS}

\section{Bench study}

Six models of tracheostomy speaking valves (table 1) were tested during a bench study. As the sixth valve was sealed to a tracheostomy tube, it was separated from its tube using a stanley knife in order to exclude the tracheal tube resistance from the analysis.
AFFILIATIONS

*Services de Réanimation Médicale, Physiologie-Explorations

Fonctionnelles et Centre d'Innovation Technologique, Hôpital Raymond

Poincaré, AP-HP, Garches,

${ }^{\#}$ Head and Neck Surgery Dept, Foch Teaching Hospital, Suresnes,

'Association d'Entraide des Polios et Handicapés (ADEP), Puteaux, and + Inserm U 651, Créteil, France.

CORRESPONDENCE

F. Lofaso

Service de Physiologie-Explorations Fonctionnelles

Hôpital Raymond Poincaré

92380 Garches

France

Fax: 33147107943

E-mail: f.lofaso@rpc.ap-hop-paris.fr

Received:

January 262005

Accepted after revision:

December 112005

SUPPORT STATEMENT

The study was supported by the Association d'Entraide des Polios et Handicapés (ADEP; Puteaux, France).

European Respiratory Journal

Print ISSN 0903-1936

Online ISSN 1399-3003 


\section{TABLE 1 The phonation valves tested}

\begin{tabular}{lcc} 
Valve & Model & Manufacturer \\
\hline V1 & Rusch 506500 & Willy Rusch AG, Kermen, Germany \\
V2 & PMV 2000 & Passy-Muir Inc., Irvine, CA, USA \\
V3 & Shiley SSV & Mallinckrodt Medical, Mirandola, Italy \\
V4 & Shiley SSVO & Mallinckrodt Medical, Mirandola, Italy \\
V5 & Rusch 00076 & AB Fogless International, Hasselby, Germany \\
V6 & Tracoe & Pouret Medical, Clichy, France \\
\hline
\end{tabular}

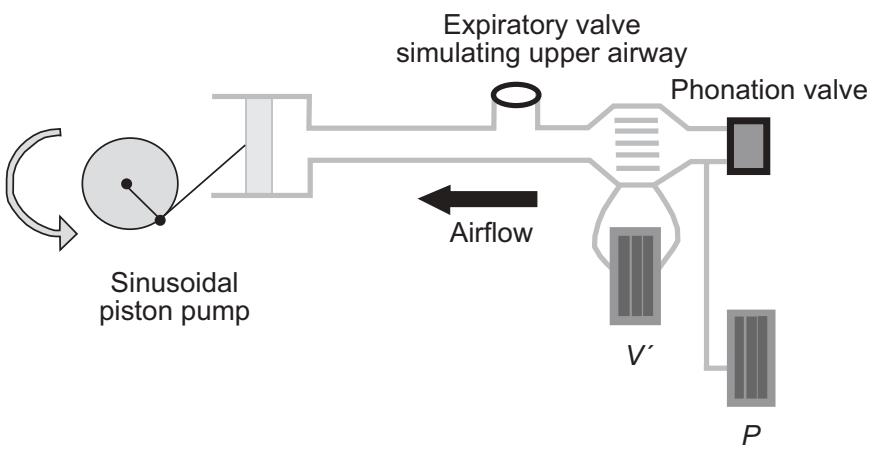

FIGURE 1. Experimental set-up. The circuit was connected to a sinusoidal pump (tidal volume $0.5 \mathrm{~L}$; peak inspiratory flow $0.5 \mathrm{~L} \cdot \mathrm{S}^{-1}$ and breathing frequency at 20 breaths $\left.\cdot \mathrm{min}^{-1}\right)$. Pressure $(P)$ and flow $\left(V^{\prime}\right)$ were measured at the extremity of the circuit.

\section{Experimental set-up}

Each speaking valve was connected to a circuit comprising a sinusoidal piston pump and an unidirectional expiratory valve (fig. 1). The speaking valve was connected to a differential transducer (MP45 $\pm 30 \mathrm{cmH}_{2} \mathrm{O}$; Validyne, Northbridge, CA, USA) and to a pneumotachograph (No. 2; Fleish, Lausanne, Switzerland) connected to a differential transducer (MP45 \pm $30 \mathrm{~cm} \mathrm{H}_{2} \mathrm{O}$; Validyne), allowing the measurement of pressure and flow. Tidal volume $(V \mathrm{~T})$ was obtained by integration of the flow signal. Signals were digitised at $128 \mathrm{~Hz}$ and sampled for subsequent analysis by an analogic/numeric acquisition system (MP 100; Biopac System, Santa Barbara, CA, USA). A software program was used to analyse the results (Acknowledge v. 7.5; Biopac System).

\section{Dynamic study}

To stimulate spontaneous breathing, the sinusoidal piston pump was set up to create a tidal volume of $0.5 \mathrm{~L}$ to obtain a breathing rate of 20 breaths $\mathrm{min}^{-1}$. Peak inspiratory flow was set at $0.5 \mathrm{~L} \cdot \mathrm{s}^{-1}$. WOB $\left(\mathrm{J} \cdot \mathrm{min}^{-1}\right)$ was estimated from the integral of the pressure-volume loops [14].

The effort required to generate inspiratory flow at each inspiration was evaluated with the pressure time product (PTP; $\mathrm{cmH}_{2} \mathrm{O} \cdot \mathrm{s}^{-1} \cdot \mathrm{min}^{-1}$ ). It was obtained from the product of inspiratory time with the pressure observed at the opening of the valve and was calculated from the pressure signal over $1 \mathrm{~min}$.

The resistance $\left(R ; \mathrm{cmH}_{2} \mathrm{O} \cdot \mathrm{L}^{-1} \cdot \mathrm{s}^{-1}\right)$ of the phonation valve was calculated at an inspiratory flow of $0.5 \mathrm{~L} \cdot \mathrm{s}^{-1}$.

The delay between the end of inspiration and the closure of the valve $(t \mathrm{D} ; \mathrm{ms})$ was also measured. Leak volume $(V \mathrm{~L} ; \mathrm{mL})$, defined as the volume escaping from the valve between the end of inspiration and closure of the valve, was obtained from the volume signal. Finally, the minimal pressure ( $P$ min; $\mathrm{cmH}_{2} \mathrm{O}$ ) observed during the ventilation cycle was measured.

\section{Patient study}

Population

In this prospective study, 10 patients were consecutively enrolled between June and November 2005. As presented in table 2, the patients were aged $>18 \mathrm{yrs}$ and $<60 \mathrm{yrs}$. All of the patients had been tracheostomised for a chronic respiratory failure as a result of neuromuscular disease. However, all of them had a vital capacity $>10 \%$ of the theoretical value [15] and were able to maintain spontaneous breathing for $\geqslant 2 \mathrm{~h}$.

Written informed consent was obtained from all subjects, and the study protocol was approved by the ethics committee of the Ambroise Paré Teaching Hospital (Boulogne, France).

\section{TABLE 2 Patient characteristics}

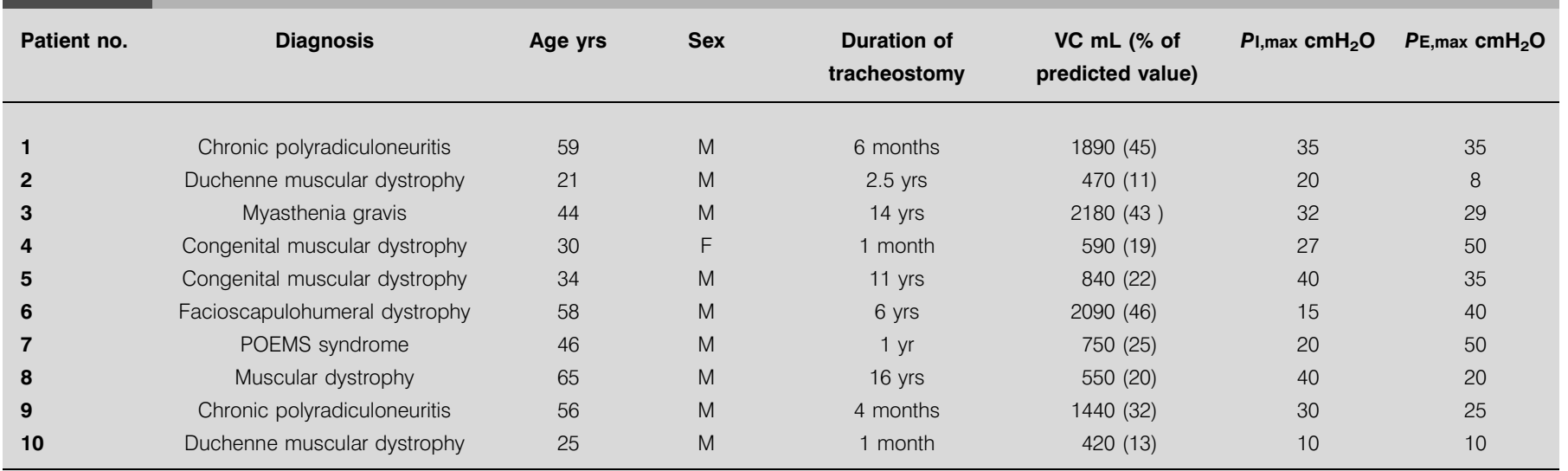

VC: vital capacity; PI,max: maximal inspiratory pressure; $P E$,max: maximal expiratory pressure, $\mathrm{M}$ : male; $\mathrm{F}$ : female; POEMS: polyneuropathy, organomegaly, endocrinopathy, M-protein and skin changes. 


\section{Experimental set-up}

Respiratory inductive plethysmography ((RIP) Respitrace Plus; Non Invasive Monitoring-Systems, North Bay Village, FL, USA) was used to obtain the breathing pattern. RIP bands were positioned on the chest above the level of the nipples and on the abdomen at the umbilical level. As previously proposed in neuromuscular patients [16], RIP was calibrated using the semi-quantitative single-position method during natural breathing (i.e. the qualitative diagnostic method [17]) and also calibrated with the integrated flow signal of a pneumotachometer (No. 1; Fleish) connected to the tracheostomy tube, while the patients wore a nose-clip and absence of leak was checked around the mouth and the tracheal tube. The patients' gas exchanges were assessed based on oxygen saturation measured using pulse oxymetry (Mallinckrodt, Hazelwood, $\mathrm{MO}$, USA) and transcutaneous carbon dioxide pressure measured using a capnograph (Radiometer TcM3; Radiometer Copenhagen, Brønhøj, Denmark). All signals were digitised at $128 \mathrm{~Hz}$ and sampled by an analogic/numeric system (MP100; Biopac Systems, Goleta, CA, USA). A software program was used to analyse the results (Acknowledge v. 7.5; Biopac System). VT, respiratory rate and inspiratory time were calculated from the computerised signal of the RIP.

\section{Experimental protocol}

After the initial bench study, the most (V1) and one of the least (V3) resistive phonation valves were selected for evaluation.

The following three conditions were applied in a random order: 1) no phonation valve; 2 ) the most resistive phonation valve; and 3) one of the least resistive phonation valves. For each condition, once a stable breathing pattern was observed for $\geqslant 10 \mathrm{~min}$, data were recorded for $5 \mathrm{~min}$.

After each condition, the subjects used the modified 10-point Borg scale to evaluate their sensation of inspiratory difficulty [18], as previously proposed in patients with a neuromuscular disorder [19]. The Borg scale is a vertical line with gradations from 0 to 10 , each gradation corresponding to a verbal description of respiratory sensation. Care was taken not to influence the subjects' responses.

\section{Statistical analysis}

All results are expressed as mean \pm SD. Differences among the three conditions were tested using ANOVA for repeated measurements. When ANOVA appeared appropriate (F test with a p-value $<0.05$ ), pairwise comparisons were performed using the Fisher's least statistical difference test. p-Values $<0.05$ were considered statistically significant.

\section{RESULTS}

\section{Bench study}

The measurements obtained from each speaking valve during the simulated patient breaths are presented in table 3 .

$R$ ranged 1.3-5.9 $\mathrm{cmH}_{2} \mathrm{O} \cdot \mathrm{L}^{-1} \cdot \mathrm{s}^{-1}$, representing a ratio of 1:4.5. Valve 6 was the least resistive with the lowest $P$ min during inspiration, whereas valve 1 showed the highest resistance and Pmin.

The additional WOB imposed by the speaking valve ranged from $0.5 \mathrm{~J} \cdot \mathrm{min}^{-1}$ for valve 6 up to $2.2 \mathrm{~J} \cdot \mathrm{min}^{-1}$ for valve 1 . Accordingly, PTP increased by a ratio of 3.5 between valve 1 and valve 6 .

Valve 2 closed almost instantly at the end of inspiration with no loss of air volume, showing it to be the most airtight. However, $V \mathrm{~L}$ was $<1 \mathrm{~mL}$ for all valves except for valve 1 $(3.5 \mathrm{~mL})$ and $t \mathrm{D}$ ranged $0-170 \mathrm{~ms}$.

\section{Patient evaluation}

Subjects

The demographic and ventilatory characteristics of the 10 subjects are reported in table 2 . Mean age was $44 \pm 16$ yrs. The subjects had severe neuromuscular respiratory failure (vital capacity $27 \pm 13 \%$ predicted) and showed an increased respiratory rate at baseline $\left(27 \pm 5\right.$ breaths $\left.\cdot \mathrm{min}^{-1}\right)$.

\section{Respiratory patterns}

Respiratory characteristics were not modified by the different conditions applied to the subjects (table 4). While all subjects had an increased respiratory rate at baseline state (with no phonation valve), it was not worsened by the addition of the different phonation valves. $V \mathrm{~T}$ was evaluated as a variation of baseline and while it showed a wide degree of variation between patients, as suggested by the standard deviation, it was not statistically significant. Likewise, gas exchanges evaluated using transcutaneous oxygen saturation and partial pressure of carbon dioxide level were not altered by the different study conditions.

TABLE 3 Dynamic measurements of phonation valve with simulated patient breaths produced by a sinusoidal pump ${ }^{\#}$

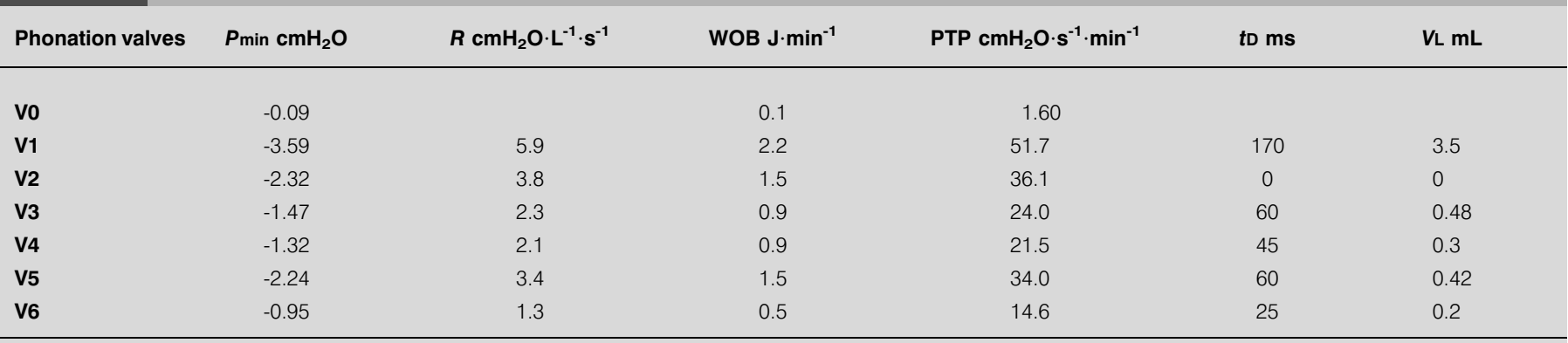

Pmin: minimal pressure observed during inspiration; $R$ : resistance; WOB: work of breathing; PTP: pressure time product; $t D$ : delay between beginning of expiration and closure of the valve; $V \mathrm{~L}$ : leak volume observed between the beginning of expiration and closure of the valve; $\mathrm{V} 0$ : measurements realised without any phonation valve. \#: using a tidal volume of $0.5 \mathrm{~L}$, a peak flow rate of $0.5 \mathrm{~L} \cdot \mathrm{s}^{-1}$ and a respiratory rate of 20 breaths $\cdot \mathrm{min}^{-1}$ 


\begin{tabular}{|c|c|c|c|c|c|}
\hline \multirow[t]{2}{*}{ TABLE 4} & \multicolumn{5}{|c|}{$\begin{array}{l}\text { Ventilatory characteristics of patients under the } \\
\text { different conditions after } 10 \text { min of breathing }\end{array}$} \\
\hline & & Baseline & Valve 3 & Valve 1 & $p$-value \\
\hline \multirow{2}{*}{\multicolumn{2}{|c|}{$\begin{array}{l}V T \% \text { of baseline value } \\
t_{1} / \text { tot }\end{array}$}} & 100 & $117 \pm 25$ & $109 \pm 27$ & NS \\
\hline & & $0.51 \pm 0.04$ & $0.52 \pm 0.06$ & $0.53 \pm 0.06$ & NS \\
\hline \multicolumn{2}{|c|}{$\begin{array}{l}\text { Respiratory rate } \\
\text { breaths } \cdot \min ^{-1}\end{array}$} & $27 \pm 5$ & $25 \pm 5$ & $27 \pm 5$ & NS \\
\hline \multicolumn{2}{|c|}{$\mathrm{Sa}, \mathrm{O}_{2} \%$} & $96.0 \pm 1.6$ & $95.7 \pm 2.3$ & $95.8 \pm 1.9$ & NS \\
\hline \multicolumn{2}{|c|}{$\mathrm{Ptc}_{\mathrm{tc}, \mathrm{CO}_{2} \mathrm{mmHg}}$} & $41.2 \pm 5.8$ & $42.7 \pm 6.6$ & $41.4 \pm 6.4$ & NS \\
\hline \multicolumn{2}{|c|}{ Borg scale 1->10 } & $1.7 \pm 2.4$ & $1.6 \pm 2.2$ & $4.6 \pm 2.6$ & $<0.003$ \\
\hline \multicolumn{6}{|c|}{$\begin{array}{l}\text { Data are presented as mean } \pm \mathrm{SD} \text {, unless otherwise stated. } \mathrm{VT} \text { : tidal volume; } \mathrm{tl} \text { : } \\
\text { inspiratory time; ttot: total respiratory time; } \mathrm{Sa}_{\mathrm{O}} \mathrm{O}_{2} \text { : arterial oxygen saturation; } \\
\mathrm{Ptc}_{\mathrm{tc}} \mathrm{CO}_{2} \text { : transcutaneous carbon dioxide pressure; NS: nonsignificant. } \\
1 \mathrm{mmHg}=0.133 \mathrm{kPa} \text {. }\end{array}$} \\
\hline
\end{tabular}

Intensity of perceived inspiratory difficulty

Borg score was influenced by the breathing condition (ANOVA $\mathrm{p}<0.003$; table 4). Moreover, it was higher with V1 (the most resistive valve) than in the baseline condition or with V3 (one of the less resistive valves; post hoc analysis $\mathrm{p}<0.02$ ), whereas none of the other post hoc analysis results were significant.

\section{DISCUSSION}

The present study demonstrates the important variety of resistance and imposed WOB presented by speaking valves. Considering that the phonation valves are manufactured by different companies with varied designs and materials, this is not unexpected.

In terms of efficiency of speech, all of the valves exhibited a very short $t \mathrm{D}(<0.1 \mathrm{~s})$. Likewise, the $V \mathrm{~L}$ observed during expiration was $<5 \mathrm{~mL}$ for all the valves, with valve 2 closing instantly on expiration and being totally airtight. Therefore, despite differences in design, all of the tested phonation valves allowed the use of almost the entire expiration time for speech.

Resistances of upper airways vary according to age [20-22]. In normal awake adults, HUDGEL et al. [21] evaluated the resistance as $3.93 \pm 0.56 \mathrm{cmH}_{2} \mathrm{O} \cdot \mathrm{L}^{-1} \cdot \mathrm{s}^{-1}$. Except for valve 1, all of the studied valves presented resistances that were comparable or below this estimation of upper airway resistance. Considering that a tracheostomy tube placed in the trachea also generates resistances $[6,7,23,24]$, this suggests that the use of a speaking valve, depending on the choice of the phonation valve, could place the subject in a situation where resistances are equal or even superior to natural total lung airway resistances.

Contrary to previous studies of characteristics of tracheostomy speaking valves $[25,26]$, the current authors tried to evaluate the theoretical additional WOB imposed on patients by the use of speaking valves.

In a study of the decannulation of nine tracheostomised patients, the average fall in WOB obtained with tracheostomy was $2.2 \mathrm{~J} \cdot \mathrm{min}^{-1}[6]$. This was attributed to the decrease in dead space and, therefore, in minute ventilation resulting from tracheotomy. The estimated additional WOB imposed by the different phonation valves tested was comparable to that for valve 1 , which was well below the value for the other valves. Therefore, WOB would be expected to increase with the addition of a speaking valve, but to stay below or equal to WOB observed after decannulation. However, with the use of speaking valves, the benefit of the decrease in dead space persists and actual WOB would need to be measured in order to confirm this hypothesis.

Likewise, CHADDA et al. [6] observed a significant decrease in diaphragmatic PTP (PTPdi) in tracheostomised patients. Compared with the decannulation situation, the average drop in PTPdi was $57 \mathrm{cmH} \mathrm{CH}_{2} \mathrm{O} \cdot \mathrm{s}^{-1} \cdot \mathrm{min}^{-1}$. Again, all the phonation valves exhibited a theoretical additional PTP close to or below that value. Valve 1 had the highest calculated PTP, whereas valve 6 showed the lowest. Therefore, according to the choice of phonation valve, the subject using the valve could be placed in a situation where the WOB and PTP are close to a decannulation situation. Whether this is of clinical significance depends on whether this situation allows the pressure-time index of the different respiratory muscles to remain below the threshold of fatigue $(\sim 0.18$ for diaphragm and 0.3 for chest wall muscles) [27-29]. Instinctively, this should be linked to the underlying condition imposing the realisation of a tracheostomy. Indeed, the additional respiratory load resulting from the use of valves might be deleterious to patients who already present an impaired respiratory function, whereas it could have no influence on subjects who are tracheostomised due to an acute condition and who are recovering from that episode.

To evaluate whether the difference in resistance and WOB observed in the bench study are clinically relevant, the current authors conducted a clinical study to compare the worst phonation valve to one of the best phonation valves and to a condition where no speaking valve was used. The clinical evaluation showed no significant impact of the different conditions tested on the respiratory pattern and gas exchanges of the patients. This could suggest that the differences observed in the characteristics of the phonation valves have little clinical impact. This is in accordance with previous studies that have subjectively and clinically evaluated phonation valves [30-33]. However, the limited duration of the evaluation may underestimate the potential fatigue induced by the additional WOB resulting from the use of the phonation valves. Nevertheless, the evaluation of the perceived inspiratory difficulty induced by the phonation valves showed a higher Borg scale rating with a higher exertion perception for the most resistive valve. The current patients presented severe restrictive respiratory failure and could, therefore, be more sensitive to variations in resistance and workload. Whether patients with less severe underlying respiratory failure would be sensitive to these variations remains to be determined.

To the current authors' knowledge, no study has investigated the actual work of breathing and physiological effects associated with the use of phonation valves in tracheostomised patients. Several studies have evaluated the tolerance of these phonation valves, but were mainly based on clinical and subjective criteria [30-33]. In the current study, while the valves were clinically rather well tolerated, a significant influence of the type of phonation device on the sensation of 
respiratory difficulty was observed. Whether the differences observed in the various conditions are clinically significant remains to be more widely studied. However, this variety should be considered in the choice of phonation valve according to the underlying disease that imposed the indication of tracheostomy. Indeed, while the increased resistance and work of breathing might be detrimental in patients presenting with various medical conditions, such as impaired pulmonary function, it could be beneficial to patients preparing for decannulation. Therefore, characteristics of phonation valves should be considered in the choice of phonation valve for specific patients.

\section{REFERENCES}

1 Bach JR, Ishikawa Y, Kim H. Prevention of pulmonary morbidity for patients with Duchenne muscular dystrophy. Chest 1997; 112: 1024-1028.

2 DeVivo MJ, Ivie CS 3rd. Life expectancy of ventilatordependent persons with spinal cord injuries. Chest 1995; 108: 226-232.

3 Heffner JE. Medical indications for tracheotomy. Chest 1989; 96: 186-190.

4 Hyatt RE, Wilcox RE. Extrathoracic airway resistance in man. J Appl Physiol 1961; 16: 326-330.

5 Nunn JF, Campbell EJ, Peckett BW. Anatomical subdivisions of the volume of respiratory dead space and effect of position of the jaw. J Appl Physiol 1959; 14: 174-176.

6 Chadda K, Louis B, Benaissa L, et al. Physiological effects of decannulation in tracheostomized patients. Intensive Care Med 2002; 28: 1761-1767.

7 Diehl JL, El Atrous S, Touchard D, Lemaire F, Brochard L. Changes in the work of breathing induced by tracheotomy in ventilator-dependent patients. Am J Respir Crit Care Med 1999; 159: 383-388.

8 Leder SB. Importance of verbal communication for the ventilator-dependent patient. Chest 1990; 98: 792-793.

9 Hoit JD, Banzett RB. Je peux parler! Am J Respir Crit Care Med 2003; 167: 101-102.

10 Bach JR, Alba AS. Tracheostomy ventilation. A study of efficacy with deflated cuffs and cuffless tubes. Chest 1990; 97: 679-683.

11 Prigent H, Samuel C, Louis B, et al. Comparative effects of two ventilatory modes on speech in tracheostomized patients with neuromuscular disease. Am J Respir Crit Care Med 2003; 167: 114-119.

12 Hoit JD, Banzett RB, Lohmeier HL, Hixon TJ, Brown R. Clinical ventilator adjustments that improve speech. Chest 2003; 124: 1512-1521.

13 Passy V. Passy-Muir tracheostomy speaking valve. Otolaryngol Head Neck Surg 1986; 95: 247-248.

14 Otis AB. The work of breathing. Physiol Rev 1954; 34: 449-458.

15 Quanjer PH, Tammeling GJ, Cotes JE, Pedersen OF, Peslin R, Yernault JC. Lung volumes and forced ventilatory flows. Report Working Party Standardization of Lung Function Tests, European Community for Steel and Coal. Official Statement of the European Respiratory Society. Eur Respir J 1993; 6: Suppl. 16, 5-40.
16 Perez A, Mulot R, Vardon G, Barois A, Gallego J. Thoracoabdominal pattern of breathing in neuromuscular disorder. Chest 1996; 110: 454-461.

17 Sackner MA, Watson H, Belsito AS, et al. Calibration of respiratory inductive plethysmograph during natural breathing. J Appl Physiol 1989; 66: 410-420.

18 Borg GA. Psychophysical bases of perceived exertion. Med Sci Sports Exerc 1982; 14: 377-381.

19 Hours S, Lejaille M, Pozzi D, et al. Perceived inspiratory difficulty in neuromuscular patients with primary muscle disorders. Neuromuscul Disord 2004; 14: 289-296.

20 Vig PS, Zajac DJ. Age and gender effects on nasal respiratory function in normal subjects. Cleft Palate Craniofac J 1993; 30: 279-284.

21 Hudgel DW, Martin RJ, Johnson B, Hill P. Mechanics of the respiratory system and breathing pattern during sleep in normal humans. J Appl Physiol 1984; 56: 133-137.

22 Hudgel DW, Devadatta P, Hamilton H. Pattern of breathing and upper airway mechanics during wakefulness and sleep in healthy elderly humans. J Appl Physiol 1993; 74: 2198-2204.

23 Hussey JD, Bishop MJ. Pressures required to move gas through the native airway in the presence of a fenestrated vs a nonfenestrated tracheostomy tube. Chest 1996; 110: 494-497.

24 Wright PE, Marini JJ, Bernard GR. In vitro versus in vivo comparison of endotracheal tube airflow resistance. $A m$ Rev Respir Dis 1989; 140: 10-16.

25 Zajac DJ, Fornataro-Clerici L, Roop TA. Aerodynamic characteristics of tracheostomy speaking valves: an updated report. J Speech Lang Hear Res 1999; 42: 92-100.

26 Fornataro-Clerici L, Zajac DJ. Aerodynamic characteristics of tracheostomy speaking valves. J Speech Hear Res 1993; 36: 529-532.

27 American Thoracic Society/European Respiratory Society. ATS/ERS Statement on respiratory muscle testing. Am J Respir Crit Care Med 2002; 166: 518-624.

28 Bellemare F, Grassino A. Effect of pressure and timing of contraction on human diaphragm fatigue. J Appl Physiol 1982; 53: 1190-1195.

29 Zocchi L, Fitting JW, Majani U, Fracchia C, Rampulla C, Grassino A. Effect of pressure and timing of contraction on human rib cage muscle fatigue. Am Rev Respir Dis 1993; 147: 857-864.

30 Passy V, Baydur A, Prentice W, Darnell-Neal R. PassyMuir tracheostomy speaking valve on ventilatordependent patients. Laryngoscope 1993; 103: 653-658.

31 Lichtman SW, Birnbaum IL, Sanfilippo MR, Pellicone JT, Damon WJ, King ML. Effect of a tracheostomy speaking valve on secretions, arterial oxygenation, and olfaction: a quantitative evaluation. J Speech Hear Res 1995; 38: 549-555.

32 Manzano JL, Lubillo S, Henriquez D, Martin JC, Perez MC, Wilson DJ. Verbal communication of ventilator-dependent patients. Crit Care Med 1993; 21: 512-517.

33 Leder SB. Perceptual rankings of speech quality produced with one-way tracheostomy speaking valves. J Speech Hear Res 1994; 37: 1308-1312. 